\title{
ADMISSIBILIDADE DAS PROVAS ILÍCITAS NO PROCESSO PENAL BRASILEIRO.
}

Lucas Whitaker Piai, Sérgio Mastellini

Universidade do Oeste Paulista - UNOESTE, Curso de Direito, Presidente Prudente. E-mail: lucaspiai@hotmail.com

\section{RESUMO}

Com a tendência de valorização dos direitos humanos, a garantia da ampla defesa em relação à liberdade probatória é discutida. $O$ objetivo deste trabalho é induzir o questionamento acerca da admissão ou não das provas ilícitas no direito processual penal brasileiro, refletindo sobre em quais contextos poderiam ser utilizadas e em benefício de qual parte, na persecução penal. Ainda, compreender os fundamentos que justificam cada ponto de vista doutrinário, visualizando-se suas implicações no plano concreto. Neste sentido, houve a apreciação do tema por meio de observação da discussão doutrinária e jurisprudencial, a fim de se entender a abordagem atual dos operadores do Direito. Por fim, verifica-se crescente discussão entre os estudiosos do processo penal sobre a polêmica acerca de seu aproveitamento, sendo significativa a manifestação favorável à utilização de provas ilícitas pela defesa, em nome de uma maior realização da ampla defesa e do contraditório.

Palavras-chave: Direito Processual Penal, Provas, Provas llícitas, Teoria dos Frutos da Árvore Envenenada, Princípio da Proporcionalidade.

\section{ADMISSIBILITY OF ILLEGAL EVIDENCE ON THE BRAZILIAN CRIMINAL PROCEDURAL LAW}

\begin{abstract}
With the current tendency of human rights, the guarantee of broad defense and the probationary freedom are discussed. The goal of this paper is to induce questioning about the use of illegal evidence in the national criminal procedural law, considering its use in a number of contexts and by which parts of the criminal process. Still, understanding the foundations of each doctrinaire point of view in order to project their implications on the concrete plan. In this sense, the subject of this paper has been appreciated by the observation of the jurisprudence and doctrinaire discussion about its controversial exploitation. Lastly, there is a growing debate about this matter, while there is a significant amount of law operators that are favorable to the use of illegal evidence by the defense, on behalf of a bigger achievement of broad defense and adversarial guarantee.
\end{abstract}

Keywords: Criminal Procedural Law, Evidences, Illegal Evidences, Fruit of the Poisonous Tree, Principle of Proportionality. 


\section{INTRODUÇÃO}

Nos primórdios da humanidade, não havia a noção de Direito como ciência de fato, pois a resolução dos conflitos e consequente determinação do vencedor era sempre realizada pelos mais fortes. Pela preponderância do indivíduo dominante, era desnecessária a figura da prova - não havia uma racionalização da discussão.

Posteriormente, com a evolução social, surgiram os primeiros mecanismos de prova. Dada a importância da religião à época, tida como base da sociedade, não é inesperado que o Direito possuísse origem divina. Os meios de prova eram ligados diretamente com a religião, como as provas ordálias, juramentos e até combates judiciários.

Com o inevitável avanço da sociedade, houve o desenvolvimento e o fortalecimento do Estado, que acabou por interferir na resolução de conflitos entre os indivíduos. Surgiu, então, a arbitragem obrigatória, visando a solução dos conflitos sem a presença da religião - marcando, assim, o início da hegemonia da justiça pública sobre a privada.

Isto posto, a demonstração e comprovação dos fatos trazidos à discussão tornou-se necessária para viabilizar a satisfação da pretensão. A produção de provas, comprovando ou invalidando os fatos, passou a significar a diferença entre a vitória e a derrota no processo.

O presente estudo tem por objetivo refletir sobre a utilização ou não, no direito processual penal, de provas obtidas ilicitamente e suas derivadas, bem como em quais situações seria aceitável o seu aproveitamento pro reo ou pro societate.

A questão em foco é de extrema importância, tendo em vista que instigará a discussão de acadêmicos acerca do tema, proporcionando novos questionamentos e entendimentos, levando a novos apontamentos científicos e contribuições no âmbito de pesquisas.

\section{METODOLOGIA}

O presente trabalho teve seu desenvolvimento por meio de diversas pesquisas bibliográficas, leituras, artigos eletrônicos, e observação do tema em seu desenvolvimento prático ante a realidade jurídica. Discussão principalmente por meio do emprego do método hipotéticodedutivo.

\section{RESULTADOS}

Em sintonia com o avanço da tecnologia e das demais áreas de interesse humano, a ciência jurídica também tem evoluído. Com seu amadurecimento, a função das provas tornou-se cada vez mais importante. Nas palavras de Marcão (2017, p. 437):

Em sentido estrito, prova é a informação ou o conjunto de informações determinadas, trazidas aos autos em que materializada a persecução penal, por iniciativa do Delegado de Polícia, das partes no processo, pelo juiz ou por terceiros. Trata-se de uma reconstrução histórica subjetivo-objetiva que tem por escopo demonstrar as razões e a dinâmica do fato passado.

Regida pela implacável ação do tempo, a inevitável transformação de conceitos, interpretações e noções, acaba por consolidar o Direito como dinâmico, mutável, em contraste com a outrora noção de dogma que possa ter adquirido antigamente.

$\mathrm{Na}$ esteira dessas transformações está a atual valorização dos direitos humanos e a flexibilização de comandos constitucionais expressos. Com a crescente tendência garantista, há uma maior valorização dos direitos humanos e garantias fundamentais dos indivíduos, entrando em cena a discussão acerca da aceitação ou não das provas ilícitas no direito processual penal.

Como muito bem conceituado e exemplificado: "Prova ilícita é aquela cuja obtenção viole princípios constitucionais ou que contraria normas de direito material, tais como a confissão mediante tortura e a interceptação telefônica não autorizada judicialmente." (SILVA; FREITAS, 2012, p. 274). 
O Poder Legislativo Constituinte determinou, em seu art. 5ㅇ, inciso LVI, que "são inadmissíveis, no processo, as provas obtidas por meios ilícitos", entretanto, tal determinação constitucional não deve ser interpretada isoladamente, rigidamente, e sim de maneira sistemática, em consonância com as demais normas presentes na Carta Magna, resultando, assim, em uma aplicação da norma ao caso concreto de maneira mais justa e realista.

Ainda, de maneira diversa das provas ilícitas, existem as provas derivadas das ilícitas, sendo, estas, obtidas de acordo com as determinações legais. Entretanto, pela aplicação da Teoria da Árvore dos Frutos envenenados, estas também são descartadas. (PACELLI, 2017).

Para Távora e Assumpção (2012, p. 23):

A produção de prova ilícita pode ser de extrema prejudicialidade ao processo. Os efeitos da ilicitude podem transcender a prova viciada, contaminando todo o material dela decorrente. Em um juízo de causa e efeito, tudo o que é originário de uma prova ilícita seria imprestável, devendo ser desentranhado dos autos.

Assim, é neste contexto fático e circunstancial que se encontra a discussão sobre o aproveitamento das provas antijurídicas e suas derivadas, sendo de extrema relevância na dinâmica judicial hodierna.

\title{
DISCUSSÃO
}

Moraes (2014), assim como considerável parte da doutrina, afirma ser aceitável o aproveitamento de provas ilícitas e derivadas somente quando estas favorecerem o réu. 0 acusado, como indivíduo visado na persecução penal, teria direito de se defender amplamente das investidas do Estado, podendo, inclusive, valer-se de provas ilícitas ou derivadas para provar sua inocência.

O não aproveitamento de provas ilícitas pode resultar em efetiva injustiça, se considerarmos casos em que seja a única maneira de o réu provar sua inocência. Seria o estrito respeito ao procedimento de formação probatória mais importante do que a liberdade de um inocente? $\mathrm{O}$ acusado, por possuir, geralmente, menor capacidade processual do que o Estado, pode sofrer com um desequilíbrio de armas no processo.

Sobre a relativização da sua proibição constitucional, ensina o eminente Ministro do STF (2014, p.117):

\begin{abstract}
Saliente-se, porém, que a doutrina constitucional passou a atenuar a vedação das provas ilícitas, visando corrigir distorções que a rigidez da exclusão poderia levar e casos de excepcional gravidade. Esta atenuação prevê, com base no Princípio da Proporcionalidade, hipóteses em que as provas ilícitas, em caráter excepcional e em casos extremamente graves, poderão ser utilizadas, pois nenhuma liberdade pública é absoluta, havendo possibilidade, em casos delicados, em que se percebe que o direito tutelado é mais importante que o direito à intimidade, segredo, liberdade de comunicação, por exemplo, de permitir-se sua utilização.
\end{abstract}

Os defensores desta corrente de pensamento entendem ser razoável, excepcionalmente, a sua utilização quando em cheque estiver direito valiosíssimo, como a liberdade do indivíduo, especialmente um inocente.

Com o objetivo de se mitigar a proibição legal e constitucional, utiliza-se o princípio da proporcionalidade para, em casos específicos, relativizar direitos e garantias fundamentais, permitindo-se, assim, a utilização de provas ilícitas favor rei.

A mais alta corte do país acolhe a utilização de provas ilícitas pro reo, sempre de modo anormal, defendendo sua licitude por meio de sua "descontaminação" pela legítima defesa, causa de excludente de ilicitude que realça o poder de ampla defesa do acusado. Neste sentido foi o entendimento do Supremo Tribunal Federal no Al 50.367-PR, publicado no Diário de Justiça em 04/03/2005, da 2a Turma, Relator Min. Carlos Velloso: 
EMENTA: CONSTITUCIONAL. PENAL. GRAVAÇÃO DE CONVERSA FEITA POR UM DOS INTERLOCUTORES: LICITUDE. PREQUESTIONAMENTO. Súmula 282-STF. PROVA: REEXAME EM RECURSO EXTRAORDINÁRIO: IMPOSSIBILIDADE. Súmula 279-STF. I. - gravação de conversa entre dois interlocutores, feita por um deles, sem conhecimento do outro, com a finalidade de documentá-la, futuramente, em caso de negativa, nada tem de ilícita, principalmente quando constitui exercício de defesa. (...) (Al 50.367-PR, 2a a. Turma. Rel. Min. Carlos Velloso. J. 01/02/05. DJ 04/03/05.)

Contudo, há parte da doutrina que considera completamente inadmissíveis as provas ilícitas de qualquer tipo e para qualquer finalidade, preservando, assim, o devido processo legal. Marcão (2017) defende que não seria condizente que algumas provas ilícitas fossem aceitas e outras não, se todas elas são revestidas pelo manto da ilegalidade. Devem, portanto, ser desentranhadas do processo e descartadas.

Pacelli (2017) aponta que sua inadmissão objetiva proteger o acusado de eventuais abusos cometidos pelo Estado durante a persecução penal, de maneira que as provas a serem realizadas devem obedecer determinação legal, garantindo, assim, legalidade ao processo e proteção ao réu.

Na mesma seara, sobre a limitação quando da obtenção das provas, aduz Corrêa (2006, p. 14):

Conquanto no processo penal o objetivo da instrução probatória seja a busca da verdade real - material ou histórica -, na fase hodierna, de evolução dos direitos e garantias fundamentais e afirmação dos direitos humanos, além da distância temporal entre o ocorrido e a sua reconstituição no processo, aquele objetivo não pode ser perseguido de forma absoluta, estando submetido a limitações e proibições formais e materiais.

Aranha, por sua vez, (1994, p. 49) assevera que: "ao colher-se a prova, ofendidos são os direitos e garantias fundamentais do indivíduo, a prova fica fulminada pela inconstitucionalidade, não podendo prevalecer em qualquer campo do direito."

Ainda, ao contrário das provas ilícitas propriamente ditas, que são obtidas de maneira antijurídica, as provas derivadas das ilícitas não são obtidas ilegalmente. São estas produzidas seguindo as determinações da lei acerca dos elementos probatórios e o due law process.

Pacelli (2017) que, contudo, em nome de uma maior proteção das garantias da pessoa humana e de uma maior eficácia dos princípios e normas constitucionais, estende-se a estas o rigor conferido às provas ilícitas.

Neste sentido é a Teoria dos Frutos da Árvore Envenenada, ou fruits of the poisonous tree doctrine. Analogicamente, se a prova anterior é ilícita (envenenada), as provas subsequentes (frutos), desta exclusivamente vindas, também o serão.

A supramencionada teoria caracteriza-se como a consequência lógica do princípio da inadmissibilidade das provas ilícitas. Caso permitida fosse a obtenção da prova derivada da ilícita, ainda que de maneira legal, concretamente acabaria por ocorrer uma quase legalização da prova ilícita, sendo a proibição da utilização das derivadas uma imposição do princípio constitucionalmente esculpido no inciso LVI do seu art. 5‥ (PACELLI, 2017).

Acolhida pelo ordenamento jurídico brasileiro, esta teoria encontra-se delineada na primeira parte do $\S 1$ ㅇ do artigo 157 do Código de Processo Penal. (BRASIL, 1941).

Ainda, minoritariamente, há os que consideram possível a utilização das provas ilícitas e derivadas, excepcionalmente, também pro societate, baseando-se no fundamento da efetivação da justiça. Por mais que uma prova tenha sido colhida fora do molde legal ou constitucionalmente estabelecido, a correta punição do réu culpado seria justificável para a mitigação do comando proibitivo constitucional em tela. (ARANHA, 1994).

É necessária, entretanto, verificação eficiente do mal causado - restrição a direito fundamental - e do bem com isto almejado - realização da justiça - para que se justifique a aplicação de tais provas no processo penal, contra o réu. 
Enfim, busca-se, segundo a corrente doutrinária que preza pela inadmissibilidade de evidências ilícitas, proteção aos direitos e garantias fundamentais do acusado, de modo a assegurar que este obtenha processo revestido de legalidade e legitimidade.

Todavia, autores favoráveis ao aproveitamento defendem que, por meio de sua utilização, especialmente favor rei, essas mesmas garantias estariam sendo priorizadas e até alcançadas, nos casos em que as normas figuram como verdadeiras barreiras à concreta realização da justiça.

Para resolver esse impasse, há que se fazer relevante ponderação de direitos e garantias. Como afirma Moraes (2014), surgirão momentos em que haverá conflitos entre esses direitos fundamentais protegidos, cabendo, nesses casos, uma relativização de um em função de outro, tendo como escopo a efetiva realização da justiça. Para essa valoração, busca-se a máxima observância dos direitos fundamentais envolvidos e sua mínima restrição compatível com a situação concreta.

\section{CONCLUSÃO}

Como é notório, o principal escopo do Direito Penal é tutelar o convívio entre os indivíduos e os seus interesses sociais, partindo do Princípio da Dignidade da Pessoa Humana; e do Direito Processual Penal, por sua vez, regulamentar as formas pelas quais essa tutela será exercida pelo Estado.

Entretanto, quando o seguimento estrito às leis acaba por gerar injustiças, verifica-se uma inversão de valores. A preferência pelo rígido ditame legal, em detrimento da efetiva realização do objetivo essencial da norma no caso concreto, mostra-se não só uma contradição jurídica, como uma oficialização de uma irregularidade.

Quando não se aceita uma prova ilícita produzida pela defesa, prova cabal da inocência do acusado perseguido criminalmente, apenas por não ter sido produzida sob os moldes legalmente estabelecidos, há que se questionar. Há a aceitação do Estado, mesmo que tácita, de certa forma, da violação da ampla defesa e do contraditório.

Contudo, a nova dinâmica do Direito tem acendido a chama da discussão acerca do aproveitamento das provas ilícitas no processo penal brasileiro. Tem-se constatado decisões favoráveis à sua utilização pro reo, em homenagem à ampla defesa e à dignidade da pessoa humana, objetivando-se obter julgamentos mais condizentes com a verdade real, e não somente a processual.

Ainda, há o questionamento sobre sua utilização pro societate, também como forma de consecução da realização da justiça - in casu, a condenação de um culpado - quando as normas legais se tornem amarras que acabam por proteger injustamente o réu da devida punição estatal, muitas vezes clamada pela sociedade.

É necessária, portanto, a observação da questão com ângulo mais realista, concreto, ao invés da velha concepção do Direito com os olhos vendados. A apreciação de cada caso deve ser aprofundada e detalhada, de modo que, em cada um deles, a prestação do serviço jurisdicional seja sinônimo de justiça, e não de institucionalização do injusto.

\section{REFERÊNCIAS}

ARANHA, Adalberto José Q. T. de Camargo. Da prova no processo penal. 3ạ ed. São Paulo: Saraiva, 1994.

BRASIL. Código de processo penal. Decreto-lei no 3.689 de 03 de outubro de 1941. Disponível em: <http://www.planalto.gov.br/ccivil_03/decreto-lei/Del3689Compilado.htm>. Acesso em: 11 set. 2017. 
BRASIL. Constituição (1988). Constituição da República Federativa do Brasil. Brasília: Senado Federal, $1988 . \quad$ Disponível em: <http://www.planalto.gov.br/ccivil_03/constituicao/constituicaocompilado.htm>. Acesso em: 11 jun. 2018.

BRASIL. Supremo Tribunal Federal. EMENTA: CONSTITUCIONAL. PENAL. GRAVAÇÃO DE CONVERSA FEITA POR UM DOS INTERLOCUTORES: LICITUDE. PREQUESTIONAMENTO. Súmula 282-STF. PROVA: REEXAME EM RECURSO EXTRAORDINÁRIO: IMPOSSIBILIDADE. Súmula 279-STF. AI 50.367PR, 2a. Turma. Rel. Min. Carlos Velloso. J. 01/02/05. DJ 04/03/05.). Al503-617-7-PR. Agravante: Ronaldo Echtein de Andrare. Agravado: Ministério Público do Estado do Paraná. Relator Min.

Carlos Velloso. Brasília, 01 de fevereiro de 2005. Disponível em: <http://redir.stf.jus.br/paginadorpub/paginador.jsp?docTP=AC\&doclD=362535>. Acesso em: 27 ago. 2018.

CORRÊA, Sílvia Leme. A prova processual penal ilícita e a teoria da proporcionalidade. 2006. $100 \mathrm{f}$. Dissertação (Mestrado em Ciências Jurídicas) - Universidade Federal do Paraná, Curitiba, 2008.

MARCÃO, Renato. Curso de processo penal. 3 ed. São Paulo: Saraiva, 2017. Disponível em: <https://integrada.minhabiblioteca.com.br/\#/books/9788547218751/cfi/604!/4/4@0.00:15.3>. Acesso em: 13 jun. 2018.

MORAES, Alexandre de. Direito constitucional. 31 ed. São Paulo: Atlas, 2015.

PACELLI, Eugênio. Curso de processo penal. 21. ed. São Paulo: Atlas, 2017. Disponível em: <https://integrada.minhabiblioteca.com.br/\#/books/9788597010268/cfi/6/10!/4/18@0:88.1>. Acesso em: 18 jun. 2018.

SILVA, M. A. M.; FREITAS, J. W. Código de processo penal comentado. São Paulo: Saraiva, 2012.

TÁVORA, N.; ASSUMPÇÃO, V.. Processo penal II. Provas - Questões e processos incidentes. São Paulo: Saraiva, 2012. 